
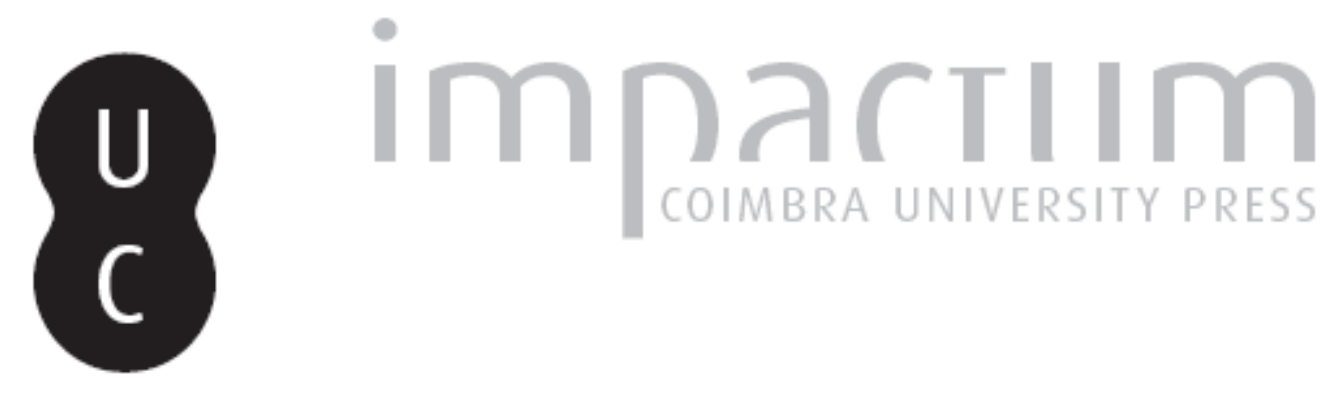
Feminina e não feminista: a construção mediática do backlash, do consumo e dos
pós-feminismos

Autor(es): $\quad$ Souza, Juliana Mello

Publicado por: Imprensa da Universidade de Coimbra

URL persistente:

URI:http://hdl.handle.net/10316.2/42813

DOI:

DOI:https://doi.org/10.14195/2183-5462_30_5

Accessed : $\quad$ 26-Apr-2023 15:10:42

A navegação consulta e descarregamento dos títulos inseridos nas Bibliotecas Digitais UC Digitalis, UC Pombalina e UC Impactum, pressupõem a aceitação plena e sem reservas dos Termos e Condições de Uso destas Bibliotecas Digitais, disponíveis em https://digitalis.uc.pt/pt-pt/termos.

Conforme exposto nos referidos Termos e Condições de Uso, o descarregamento de títulos de acesso restrito requer uma licença válida de autorização devendo o utilizador aceder ao(s) documento(s) a partir de um endereço de IP da instituição detentora da supramencionada licença.

Ao utilizador é apenas permitido o descarregamento para uso pessoal, pelo que o emprego do(s) título(s) descarregado(s) para outro fim, designadamente comercial, carece de autorização do respetivo autor ou editor da obra.

Na medida em que todas as obras da UC Digitalis se encontram protegidas pelo Código do Direito de Autor e Direitos Conexos e demais legislação aplicável, toda a cópia, parcial ou total, deste documento, nos casos em que é legalmente admitida, deverá conter ou fazer-se acompanhar por este aviso.

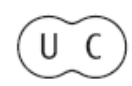


Media Jornalismo Imprensa da Universidade de Coimbra / Coimbra University Press 2 N. 30 Vol. 17, N. . 1 - 2017

\section{MULHERES E MEDIA}




\title{
FEMININA E NÃO FEMINISTA: \\ A CONSTRUÇÃO MEDIÁTICA DO BACKLASH, DO CONSUMO E DOS PÓS-FEMINISMOS
}

\author{
FEMININE AND NON-FEMINIST: \\ THE MEDIATIC CONSTRUCTION OF BACKLASH, \\ CONSUMPTION AND POST-FEMINISMS
}

\begin{abstract}
JULIANA MELLO SOUZA
Universidade de Coimbra. Centro de Estudos Sociais (CES), 3000-995 Coimbra, Portugal jmellosouza@gmail.com
\end{abstract}

Resumo

A significativa intervenção dos feminismos na identificação e na desconstrução das práticas sociais ainda dominantes, logo, na emersão de novas perspetivas de mudança, sempre foram obscurecidos e negligenciados, se não mesmo tornados ausentes, no debate com o grande público.

Dado o impacto da nova linguagem mediática em torno dos feminismos parece-nos importante o exercício de passar em revista como os constructos neoliberais dos feminismos, sobretudo apropriados pelos veículos de comunicação social, podem ser observados e interpretados como um fenómeno social que envolve, no seu modus operandi, tanto as estruturas de controlo/poder como as lógicas identitárias de uma sociedade marcadamente patriarcal. É o que se pretende fazer no presente artigo.

\section{Palavras-chave \\ Neoliberalismo; Feminismos; Media e Identidade}

\section{Abstract}

The significant intervention of feminisms in the identification and deconstruction of the dominant social practices and, therefore, in the emergence of new perspectives of change, have always been obscured and neglected, if not absent, in the debate with the general public.

Given the impact of the recent media language on feminisms, the analysis of how neoliberalism constructs feminisms, as appropriated by the media seems an important task, particularly as they can be seen and interpreted as a social phenomenon involving, in its modus operandi, both the control / power structures and the identity logics of a strongly patriarchal society. This review is the aim of our article.

KEYWORDS

Neoliberalism; Feminism; Media and Identity 
INTRODUÇÃO

Os feminismos e muitas das suas propostas acerca das políticas de identidade se revelam de fundamental importância para a criação de novos espaços, inclusive ou principalmente discursivos nos quais se inscreva a diversidade de identidades, procurando construir uma política da diferença que desestabilize as culturas normativas binaristas indexadas ao caráter biológico dos sujeitos. 0 movimento feminista subverte e debate, a vários níveis, as construções dicotómicas e heteronormativas em torno dos diferentes sexos, profundamente marcadas pelo género, e as suas respetivas inscrições na sociedade, permitindo assim novos discursos e novas interlocuções. E estabelecer interlocuções com os meios de comunicação para que se discutam publicamente questões até agora despolitizadas permite criar novos discursos públicos e novas perspetivas de entendimento da realidade, bem como desconstruir e deslocar elementos hegemónicos dos meios de interpretação e de comunicação (Fraser, 1989, cit. por Silveirinha, 2001). Dada a importância dos media enquanto estratégia de (re)produção da realidade, os feminismos de hoje, como manifestação de atividade de contra-públicos, pretendem a integração das questões de género na cultura jornalística, em geral e, especificamente, nas suas rotinas de produção.

Assim, este artigo procura compreender essas propostas de subversão das lógicas identitárias binárias subjacentes às múltiplas dinâmicas do discurso mediático, nomeadamente as que estão presentes nas produções dirigidas ao dito "público feminino". Pretende-se ainda refletir sobre a possibilidade de a narrativa jornalística, nestes termos, funcionar como meio de informação crítica distanciado do Estado e da economia oficial, perspetivando o seu público como cidadão/ã e não enquanto consumidor/a, como propõe Maria João Silveirinha (2001). Trata-se assim de um exercício de reflexão (que tem, inclusivamente, uma componente de caráter pessoal) sobre a forma como se constrói nos media, em particular nas revistas dirigidas a esse público, tanto a presença como a ausência das mulheres enquanto sujeito social, enquanto parte de um discurso social. 0 que parece ser um enorme paradoxo é, para este artigo o fato de, a um determinado nível, as publicações atuais voltadas para o público dito "feminino" se apresentarem, explícita ou implicitamente, como defensoras "pós-feministas" de uma ideia de "empoderamento" das mulheres, sugerindo a possibilidade de liderança, liberdade sexual, autonomia financeira, entre outras, enquanto, por outro lado, são claramente um dos dispositivos discursivos que mais expõe, reforça e naturaliza modelos de comportamento e sedimenta as (já históricas) posições estanques das mulheres na sociedade.

\section{UM FEMININO QUE OPRIME}

0 exercício para melhor compreender a perspetiva mediática neoliberal sobre as mulheres nos dias de hoje passa necessariamente pela análise do papel dos respetivos conteúdos no estabelecimento de normas sociais. A forma como os conteúdos veiculados por diversas publicações orientam a construção de comportamentos e definem "orientações de ação e a identificação de possíveis posicionamentos, práticas e subjetividades" (Magalhães, 2011) face a um modelo de feminilidade heteronormativo e neocapitalista tem sido determinante na construção de referenciais identitários. Por exemplo, no que se refere à heteronormatividade compulsória (Wittig, 1992), é de se ter conta que a produção mediática frequentemente explora esta prática, inclusi- 
vamente as publicações dirigidas ao público dito "feminino". 0 objetivo parece ser 0 de marginalizar ou invisibilizar a discussão crítica sobre as diferenças, minimizando, assim, ações de resistência e de questionamento, como, por exemplo, os feminismos.

Mas há um ponto aqui de fundamental importância para a discussão que se lança: a reflexão em torno dos principais mecanismos que configuram e determinam os ideais de feminilidade (re)produzidos pela retórica mediática. Isso porque os modelos de conduta no processo subjetivo de assimilação e de articulação com os referenciais de identidade "aceites", apropriados e (re)construídos ao longo do historial de vida de cada um de nós (Magalhães, 2011), são filtrados pelos media. Assim, a interferência dos veículos de comunicação de massa na formação e na difusão de códigos de conduta a serem aceites social e culturalmente ou, ainda, de modelos de comportamento e de representação, sobretudo quando nos referimos às mulheres, passa a ser decisiva.

Ao repensar os modelos (heteronormativos) do que significa ser feminina/o, problematizando, assim a própria "aceitação" da feminilidade num contexto contemporâneo, devemos refletir acerca de uma outra questão transversal ao debate: as concepções acerca das relações e das práticas socioculturais que hoje assimilamos, de forma a mostrar como os media', parte de um conjunto de forças que dinamizam e (re)organizam o mundo social, homogeneiza e essencializa as diversas identidades sociais, em especial a que é construída para as mulheres.

Existem várias formas pelas quais se pode conceptualizar a relação entre a narrativa mediática e as construções sociais dos papéis femininos e masculinos. Uma dessas construções é a figura dos feminismos, frequentemente representada em oposição aos ideais de feminilidade (re)criados pelas instâncias mediáticas e ainda apresentada enquanto prática "desviante" de um quotidiano que prima pela condição pessoal, algo largamente aclamado pelo dito pós-feminismo da cultura popular (Magalhães, 2011), em detrimento de uma agenda combativa de lutas sociais, contra, por exemplo, a discriminação de género.

Um significativo número de feministas e de investigadoras/es, sobretudo nas áreas dos estudos de género e dos estudos das mulheres, creditam aos media uma evidente responsabilidade pelo desequilíbrio na construção de uma perspectiva de género no processo de composição e de difusão da narrativa jornalística dirigida as mulheres. Isso acaba por contribuir para uma (re)produção estanque e distorcida (Thornham, 2006) de referenciais no que diz respeito tanto aos homens como às mulheres - mas, principalmente, estas últimas. Sobre esta questão, Maria João Silveirinha, em As Mulheres e os Media(2004), assinala que os feminismos, de uma maneira geral, entendem e trabalham o discurso mediático como a "voz de um poder que secundarizou e viu as mulheres de uma determinada forma" (2004: contracapa), forma esta que, como reforçam outras autoras, ao remeter desde sempre as mulheres para papéis essencialmente circunscritos à casa, marginalizou-as "em relação às instituições de poder político, bem como da transmissão do conhecimento e de formação profissional", (Macedo \& Amaral, 2005: 145). Tal representação parcial da realidade social das mulheres por parte dos media vem, assim, reproduzindo e reforçando as já profundas assimetrias de género ao longo das últimas décadas.

1 Entendo serem os media um espaço de (re)construção de identidades por excelência, trazendo as suas escolhas comerciais à superfície de uma vida quotidiana determinada por modelos de consumo. 
Por outro lado, devido à agenda de perfil contestatário e combativo que muitos dos movimentos sociais de emancipação empreendem, a grande imprensa olha com uma certa ressalva para os horizontes de construção e de representação dos feminismos, gerando, por sua vez, uma relação muitas vezes tensa entre os media noticiosos e este movimento de contestação social (El Yamani, 1998; Arús et al. 2000; van Zoonen, 2000; Gallego, 2004), os feminismos. Na verdade, o incómodo que as temáticas sociais causam dentro das redações jornalísticas acaba por subestimar ou mesmo menorizar o impacto que estes discursos têm no terreno social e, assim, emudecer a perspetiva feminista e de (igualdade de) género no processo democrático. Esta praxis, por sua vez, acaba por expor as franjas de uma rotina organizacional dos meios comunicacionais, regida por interesses comerciais, os quais primam por uma "cultura jornalística" (Gallego, 2004) de caráter sexista, que hierarquiza e estabelece critérios de relevância para as notícias (Birolli, 2010), em que os feminismos dificilmente estão presentes. Nesta perspetiva, são muitos os/as autores/as que adotam a defesa de uma prática pela qual os/as jornalistas procurem levar em conta esse desfoque do caráter combativo dos movimentos contestatários, viabilizando, assim, a construção de uma identidade pública dos movimentos feministas nos mediae, por conseguinte, na sociedade.

É por isso urgente, como propõe Maryame El Yamani (1998), que as mulheres se apropriem de um discurso próprio e alternativo, tanto generalista como especializado, e que façam definitivamente parte do processo de (re)produção da informação nas suas sociedades, nos mais diversos contextos culturais, para que passem a ser mais sujeitos do que objetos da informação mediática. Logo, para uma multiplicidade de debates e uma reinscrição da dinâmica social a partir da perspetiva das mulheres - se possível, feminista, pois, como sublinha El Yamani, "la lecture féministe de la réalité détecte les opressions quelles qu'elles soient" (1998: 15) -, deve-se quebrar paradigmas e refletir em torno da necessidade de transformação do estatuto social das mulheres.

Essa transformação do estatuto e dos papéis sociais tradicionalmente atribuídos às mulheres, consolidados sobretudo no ideal de feminilidade, requer uma alteração estrutural dos paradigmas patriarcais, os quais, por sua vez, regulam e definem o ordenamento de toda uma sociedade. É assim que a resistência das instâncias mediáticas a contemplar as ideias ditas "feministas" encontra a sua própria legitimação.

Ainda nestes termos, a julgar pelo que tem sido retratado por uma considerável parcela do jornalismo mainstreaming - sem ainda referir aquele que é segmentado e dirigido às mulheres - nota-se que, em muitos casos, em nome de uma pretensa "democracia das diferenças" e de uma tentativa de "incorporação atenta às mudanças sociais" no conteúdo redatorial, as abordagens relativas aos movimentos feministas são habitualmente construídas a partir de certas anuências editoriais, com pequenas concessões, dentro do que grande parte do jornalismo entende como um quadro feminista pseudo liberal. A partir destas constatações, a investigadora Elisabeth A. van Zoonen $(1992,2004)$ explica que as concessões dos padrões jornalísticos ortodoxos a que se assiste é habitualmente feita se a narrativa jornalística tiver em conta na sua abordagem - ressignificada - pelo menos uma das três condições seguintes: 1) a emancipação é legítima, mas os feminismos são desviantes (em relação a uma heteronormatividade compulsória); 2) as ativistas do movimento são "anarquistas", demasiado diferentes das normas, e não representam as mulheres "comuns" (e sim a antítese dos ideais de feminilidade) e 3) os movimentos feministas são sempre dirigidos contra os homens. 
Para van Zoonen, parte desse processo de consolidação de um discurso androcêntrico passa pela representação que é feita dos feminismos na imprensa, ou seja, pela ofensiva ideológica em torno dos movimentos e a consequente subjugação e/ ou ressignificação do seu ideário. 0 que se nota, portanto, é que o discurso da transformação e da reorientação de paradigmas políticos e da transformação do estatuto social das mulheres defendidos pelos movimentos feministas recai sobre uma avaliação muitas vezes torpe por parte dos media. Com isso, van Zoonen sugere que é imprescindível aprofundar a análise e a discussão desta representação social e política dos feminismos tão secundária e difusa (re)produzida pela imprensa mainstreaming.

Mesmo que ainda não despertem, por via de regra, especial interesse na agenda político-económica dos grandes acontecimentos, os movimentos feministas já começam a se instalar e a surtir algum efeito nos valores das notícias e nas rotinas organizacionais dos veículos de comunicação social - exemplo notório tem sido a cobertura mediática internacional das marchas feministas de resistência aos regimes neoconservadores e totalitários, como o de Donald Trump (recentemente eleito para a presidência norte-americana).

Por outras palavras, a construção social da identidade pública dos movimentos feministas, tal como grande parte dos novos movimentos sociais, bem como as interações com os media que a produzem, reflete a forma como a construção social do género é desenvolvida e igualmente determinante no estabelecimento dos papéis dos homens e das mulheres. Reflete ainda e, em especial, como o conceito heteronormativo de "feminino/a", socialmente incompatível com o de feminista, dilui as reais ações interventivas dos movimentos na sociedade e cristaliza a função de serviço público que compete ao jornalismo.

Assim, as questões de género apresentam-se como determinantes na definição e na consolidação das narrativas discursivas e, por sua vez, fornecem os referenciais identitários para o processo de definição binarista e heteronormativa das posições-de-sujeito nas sociedades. Verifica-se, portanto, que para as mulheres, ou até mesmo para a opinião pública de uma forma geral, a correspondência dos feminismos ainda implica, por inerência, as noções opostas ao ideal de feminilidade. Rapidamente se verifica a inclusão de inúmeros estereótipos socialmente construídos, como o radicalismo, o anarquismo, o lesbianismo e a constante oposição aos homens, conceitos já aqui referidos.

Partindo destes pressupostos, e assumindo uma posição feminista e crítica de análise, penso que ao contemplar os feminismos na reflexão e na atividade jornalística permitimo-nos identificar e tornar visível a realidade de opressão que ainda configura o quotidiano dos sujeitos que compõem o quadro de exclusão social. Contemplar os feminismos na praxis jornalística permite-nos uma releitura da realidade a partir da perspetiva de opressão, de luta, do desejo de inovação, da circulação de ideias e de questionamentos, justamente porque 0 ideal feminista deteta as desigualdades de género tão invisibilizadas pela grande imprensa, que trabalha para favorecimento do mercado.

\section{2. "Feminina e não feminista"}

Há, naturalmente, muitas formas de se pensar sobre as questões que envolvem a representação das mulheres na atualidade, sobretudo nos termos da narrativa jornalística. No entanto, quando a abordagem se centra na temática dos feminismos, essa "palavra maldita", como ironizam Isabel do Carmo e Lígia Amâncio em Vozes 
Insubmissas (2004), uma palavra que sempre gerou repulsa por parte da sociedade (Ventura, 2012), a carga pesada de luta, que se liga nomeadamente à segunda vaga, aliada hoje aos estereótipos social e frequentemente construídos em torno da homossexualidade feminina (Gallego, 2004) - antítese dos ideais de feminilidade normativa -, trazem, como já vimos, o rescaldo de um notório sexismo e de alguma resistência nas redações jornalísticas quanto a uma abordagem mais criteriosa e crítica acerca da luta feminista.

Apesar da relevância atual das propostas feministas, visto que as suas causas e objetivos ainda não foram atingidos de forma plena, continuamos a assistir, na verdade, à articulação da representação das mulheres feministas e dos feminismos com a ideia, como já aqui foi referido, do ambíguo (em relação à heteronormatividade) ou, ainda, de uma representação e/ou de uma incorporação de comportamentos desviantes, de confronto e de resistência em relação ao sexo oposto - ou de um posicionamento contra os homens.

Logo, se a representação dos feminismos e das feministas tende a centrar-se no respetivo "caráter desviante", por referência aos parâmetros institucionais, o discurso mediático com que hoje nos deparamos não nos deixa dúvidas de que as definições hegemónicas sedimentam, por via de regra, a ideia dos movimentos feministas enquanto uma espécie de antítese da normalidade. E ser normal, dentro desses parâmetros institucionais, é ser feminina e, por sua vez, para ser socialmente aceite.

Neste contexto, os media continuam no radar de muitas feministas contemporâneas, que defendem uma profunda reavaliação da representação simbólica do género, mas, sobretudo, dos feminismos, nas mais diversas instâncias mediáticas. É 0 caso de Angela McRobbie que, no artigo "Beyond Post Feminism", de 2011, faz uma avaliação de como os ideais de feminilidade estão imbricados de forma complexa na construção das lógicas identitárias - mediados por concepções locais, patriarcais e mediáticas sobre os modelos de ser mulher. 0 resultado é o surgimento de duas variantes do que a autora denomina de "feminismo mediático", nas duas últimas décadas de mudança política e cultural: uma espécie ou de "pós-feminismo" ou de um "feminismo sofisticado" no conteúdo redatorial da grande imprensa, sobretudo das revistas impressas dirigidas ao público dito "feminino". Esse procedimento nos media veio dar azo à uma espécie de viés mediático para se abordar, numa pretensa "democracia das diferenças", alguns temas considerados "fraturantes" dos feminismos.

McRobbie traz uma importante contribuição para essa discussão ao demonstrar como a narrativa mediática em questão constrói e (re)produz formas mais "aceitáveis" e "toleráveis" de manifestações de teor emancipatório, empreendidas, por via de regra, pelos feminismos - nomeadamente junto ao público jovem. Fá-lo, segundo a autora, em nome de uma pretensa quebra de paradigmas e de uma postura mais progressista e liberal frente às mudanças socioculturais, através de uma abordagem pseudodemocrática das contestações e dos movimentos sociais, inclusivamente dos feministas. Essas instâncias mediáticas tentam aproximar estes movimentos de conceitos mediaticamente vendáveis, como, por exemplo, a sensualidade e o poder de liderança que algumas mulheres possuem, e, sob este discurso, desvincular-se da ideia estereotipada e simplificadora de mulheres "masculinizadas" - uma retórica que define o "velho" feminismo enquanto postura "masculinizada" e de limitação dos "prazeres naturais" ao sexo feminino. Este novo panorama mediático, nas palavras 
da autora: "upholds the principals of gender equality, while denigrating the figure of the feminist" (2011: 179). Isso porque a sensualidade e o poder de liderança das muIheres - formas mais "aceitáveis" e "toleráveis" de representação, numa abordagem pseudodemocrática das contestações -, na perspetiva de McRobbie, são "valores" que contrariam as premissas contestatárias e os questionamentos em torno das relações hegemónicas e binaristas de género que continuam a definir papéis e posições-de-sujeito às mulheres, denegrindo, portanto, a figura emancipatória da feminista.

A noção de um "feminismo sofisticado" discutida pela autora é igualmente utilizada para dar conta da complexa rede de significados que cerca a construção do que significa ser feminina e ser mulher nas sociedades ocidentais contemporâneas, regidas, em sua grande maioria, pela norma de uma heterossexualidade compulsória. São representações que evidenciam, assim, negociações identitárias que obrigatoriamente devem convergir para representações que não colidam e não desestabilizem 0 ordenamento social. Logo, os novos referenciais que daqui emergem indicam que a performance identitária das mulheres feministas, no conteúdo editorial das revistas de estilo de vida dirigidas ao dito "público feminino", seguem, preferencialmente, significados simbólicos, que historicamente possibilitaram o destaque das mulheres nestas instâncias mediáticas.

Para entendermos estas dinâmicas, há que ter em conta a complexidade das relações económicas e de poder que estruturam a realidade das instituições mediáticas - e que acabam por sustentar os interesses tanto do patriarcado como do capitalismo (Carter \& Steiner, 2004) -, a qual determina tanto a linha editorial das publicações como a representação dos seus atores sociais e as suas respetivas posições-de-sujeito.

A partir desta perspetiva, McRobbie entra em convergência com Michel Foucault ao situar os referenciais e as construções identitárias de um "pós-feminismo" como uma forma simbólica de poder. Para ambos os autores, dentro dos domínios do sexo e do poder, o capitalismo contemporâneo e as suas matrizes patriarcais alimentam-se da caracterização e da difusão de modelos hegemónicos, mais concretamente, nos termos da temática aqui lançada, de feminilidade, bem como da própria ressignificação dos feminismos (Fraser, 2009). 0 objetivo dessa ofensiva capitalista é delimitar as respetivas (e possíveis) posições-de-sujeito na sociedade e, assim, de criar um continuum de necessidades que consolidem e reforcem o que é ser mulher e o que é ser feminina e, por sua vez, dar fôlego ao nicho de mercado mais rentável dos segmentos editoriais e publicitários, que é o das revistas de estilo de vida dedicadas às mulheres. Nesta "governabilidade quotidiana", como cita McRobbie a partir de Foucault, a forte intervenção dos media nos ditames da moda e nos hábitos culturais naturalizam no seu público dois aspetos primordiais, os quais, por sua vez, convergem e contribuem conjuntamente para ainda consolidar todo um imprescindível sistema de invisibilidades para a manutenção das esferas de poder: 1) o feminismo de luta é algo ultrapassado e perfeitamente dispensável e 2) a feminilidade contemporânea beneficiou da luta pela igualdade de géneros empreendida pelas correntes feministas da segunda vaga, logo, é fundamental que as mulheres preservem essa tal feminilidade (e, como parte indissociável desse termo, ser feminina hoje, como já aqui exposto, significa também acompanhar/seguir códigos de conduta de consumo que viabilizam a contínua construção de um ordenamento social). 
Acrescento um outro aspeto ao processo de governabilidade quotidiana, como nos falam Foucault e McRobbie, a partir da ressignificação dos feminismos. Para Sara Magalhães (2011), a ofensiva ideológica contra os feminismos também pode ser lida através das novas roupagens que os movimentos adquiriram. Para a autora, uma vez envoltos nos ditames de conduta neoliberal, os feminismos acabaram por ser utilizados tanto para justificar e reconhecer as suas aquisições na $1^{\text {a }} \mathrm{e} 2^{\mathrm{a}}$ vaga, como para estimular "a reinvenção do sujeito feminino" (Magalhães, 2011: 71), com vista a consolidar o baluarte de todo um sistema, fruto de uma pretensa democracia inclusiva.

Quanto ao primeiro aspeto, que se refere à ideia do feminismo como um dado adquirido, esta temática é perspetivada por parte da grande imprensa, nomeadamente pelas revistas especializadas e dirigidas às mulheres, ainda como um mecanismo de controlo dos impulsos contra-hegemónicos dos feminismos e, nestes termos, é aplicável à manutenção dos papéis e das funções convencionais de género na sociedade. Assim, nesta dinâmica de resistência do discurso mediático a explorar e discutir com profundidade e rigor questões subjacentes ao quotidiano das mulheres, nos mais diversos contextos culturais, a partir de uma perspetiva feminista ou até mesmo de considerar a abordagem do próprio feminismo enquanto luta contínua no processo de emancipação das mulheres, diluem-se os ideais basilares do feminismo.

Com isso, a temática dos feminismos só é abordada se apresentar potencial de mercado e/ou se estiver alinhada aos interesses de determinados grupos do regime patriarcal-capitalista. A título exemplificativo, assinalamos o que tem sido sistematicamente defendido por Magalhães acerca da ressignificação dos feminismos, como 0 pós-feminismo nos media, que atua enquanto "sinónimo de uma representação neoliberal e individualista da mulher contemporânea" (2011: 71). Tal abordagem mediática é então construída por meio de uma apropriação conveniente, de uma "distorção e trivialização de premissas e objetivos centrais" da segunda vaga dos feminismos.

Nesta lógica operacional, encontra-se 0 argumento, com claras raízes patriarcais, de que as mulheres contemporâneas, sobretudo as mais jovens, já beneficiaram da luta pela igualdade de géneros e que, por via de regra, a realidade (positiva/ favorável) que hoje vivem não requer que desempenhem grandes papéis de contestação em lutas no palco político. Portanto, supostamente resolvidas as reivindicações feministas "do passado" e garantidas as condições de igualdade, as mulheres contemporâneas vivem o que McRobbie denominou um "pós-feminismo", que o entende como um fenómeno, como uma forma simbólica de poder "which can be understood as 'post-feminist'. There is a double entanglement, across the sociopolitical universe, as feminism is taken into account in order that it can be understood as having passed away" (2011: 179-180).

Inúmeras são as publicações especializadas e dirigidas ao público dito "feminino" que se assentam nesse backlash de ofensiva ideológica contra os feminismos (Faludi, 1993), estabelecendo, assim, as necessárias relações entre controlo ideológico, comportamento e interesses comerciais, como referido por Magalhães (2011) acerca do pós-feminismo nos media. Isso está assente no pilar ideológico das publicações desse género: defender as definições, categorias e modelos de feminilidade significa construir definições hegemónicas do que deve ser socialmente aceite como realidade e, assim, consolidar o arsenal económico que sustenta tanto a estrutura mediática como o sistema político que a detém. A retórica discursiva e imagética que contribui para a 
associação do feminismo a tais características estereotipadas pretende criar nas leitoras, principalmente as jovens, um profundo desinteresse para com os feminismos.

Será relevante notar que as mulheres mais jovens ocupam uma posição-chave neste processo de (re)construção dos referenciais heteronormativos e, por sua vez, de operacionalização das definições hegemónicas dentro desse quadro das relações entre controlo ideológico, comportamento e interesses comerciais. Quanto a este aspeto, McRobbie defende que as mulheres mais jovens, ao negarem a necessidade de uma nova política sexual - justamente por acreditarem que as ideologias feministas estão ultrapassadas e são dispensáveis, uma vez que já conquistaram a tão almejada liberdade sexual -, permitem que Ihes sejam feitas algumas "concessões" sociais, como, por exemplo, maior liberdade de escolha ${ }^{2}$ e de expressão.

Por esta via, portanto, mais do que entender o meio de comunicação como mensagem (McLuhan, 2001), ou, mais ainda, a comunicação mediada como a transmissão de mensagens com fins comerciais e publicitários, o recurso à exploração do conceito de feminilidade e dos seus padrões socialmente aceites confere às instituições mediáticas uma dinâmica que reforça a retórica heteronormativa e binarista de feminilidade em oposição à masculinidade. Em termos gerais, tal recurso sugere, pois, que há certos "padrões de género permitidos na cobertura noticiosa" (Silveirinha, 2004: 09) que podem, por sua vez, encorajar as/os leitoras/es a manterem a convicção da binaridade como regra absoluta.

Um discurso como esse, que em muito se assemelha ao backlash idealizado e promovido pela comunicação social associada a escritores opositores do feminismo (Nogueira \& Silva, 2003) na Hollywood da década de 40, alertando homens e mulheres para a possibilidade de que, se o feminismo fosse longe demais, poderia haver um backlash por parte dos homens, estanca as possibilidades de emancipação social das mulheres. Além de desencorajar uma relação de identidade com 0 pensamento feminista, sobretudo por parte de jovens mulheres, como McRobbie e Faludi salientam e já foi referido, o "movimento reativo contra o feminismo" (Nogueira \& Silva, 2003: 14), quando estrategicamente propagado, cria, paralelamente, um efeito de minimização e marginalização de temas considerados fraturantes relativos à realidade de muitas mulheres (Carter \& Steiner, 2004), estancando a possibilidade de debates críticos sobre os mesmos ${ }^{3}$, já que, como 0 discurso institucional defende, todas as reivindicações foram conquistadas.

A ideia apontada por McRobbie de que os feminismos na atual sociedade de consumo são (re)construídos, reinventados e difundidos com o rótulo de "obsoletos"

20 substantivo escolha nessa temática adquire múltiplos contornos, tendo em Judith Butler um dos seus principais alicerces. Um deles possivelmente seria a relação estreita entre a (pseudo) autonomia na escolha e o controlo de fato presente por detrás deste termo. A sensação de autonomia, de igualdade (superficial) e de libertação de que muitas mulheres acreditam usufruir representa, dentro dessa prática de "governabilidade quotidiana" (Foucault, 2002), uma das mais subtis e eficazes formas de controlo e de aprisionamento intelectual das mulheres praticado pela sociedade de consumo.

3 A título exemplificativo desta realidade, assinalamos a violência e o abuso sexual, os notórios fossos salariais e laborais ou, no caso concreto desta pesquisa, os efeitos da política de austeridade no quotidiano das mulheres e até mesmo 0 baixo incentivo institucional à participação feminina na vida coletiva e na esfera pública. Temáticas, portanto, que raramente são vistas na agenda mediática. Tal abordagem será problematizada no quarto e no sexto capítulos. 
e de que as mulheres jovens (sobretudo as que pertencem à classe média-alta, logo, aquelas com maior poder aquisitivo) têm hoje todas as condições sócio-político-culturais de sucesso para usufruírem do que acreditam ser o ápice da liberdade sexual, permite-nos levantar a hipótese de que estas jovens mulheres, sendo as potenciais leitoras de muitas das revistas dirigidas ao "universo feminino" encontram-se desarticuladas desta realidade fraturante em que se encontram muitas mulheres.

Nesta narrativa adotada pelas instituições sociais, mas, sobretudo, pelos media, que largamente adotam e apoiam a ideia de "pós-feminismo" (McRobbie, 2011) enquanto representativa de um modelo capitalista neoliberal que determina o que é "socialmente aceite" e passível de dar lucro, estas jovens mulheres que rejeitam os feminismos estão, na verdade, imersas num "gendered market" (Winship, 1987) e à margem da força motriz do discurso e da luta contestatários. Mas, enquanto isso, como aponta novamente Faludi (1993: 01), este mito,

[...] behind this celebration of women's victory, behind the news, cheerfully and endlessly repeated, that the struggle for women's rights is won, another message flashes. You may be free and equal now, it says to women, but you have never been more miserable.

Dentro desse processo de instrumentalização dos feminismos e da minimização das desigualdades sociais e de género, estar "infeliz", como refere Faludi, significa estar ainda mais vulnerável a todo um conjunto de interferências externas e internas que oprimem as mulheres, através do recurso dos dispositivos mediáticos, num processo contínuo de estabelecimento de normas sociais. E como reforça a este respeito Sara Magalhães, tais interferências acentuam um duplo padrão "para uma constante penalização social das mulheres, pela indicação de comportamentos adequados e aos quais se devem restringir, por comparação a uma atitude mais flexível para o sexo masculino" (2011: v).

0 binómio feminilidade-consumo, quando colocado no contexto de produção das narrativas jornalística e publicitária, necessita de ser situado na sua especificidade cultural e económica. A pluralidade de práticas de construção economicista dos referenciais de feminilidade está profundamente enraizada nos referenciais identitários que cada sociedade (re)cria, escorando-se, principalmente, na regulação das normas hegemónicas vigentes na vida social. Todas essas práticas reguladas e reproduzidas pelos media funcionam como uma espécie de "novos censores culturais do espaço intelectual das mulheres" (Wolf, 1992: 09). Assim, a observação analítica do ideal de feminilidade sob a perspetiva da economia simbólica pode ser um meio de evidenciar as estruturas de poder e de coerção social que contribuem para a classificação, tipificação e organização de uma sociedade. Desse modo, quando o ideário de feminilidade é definido através do trabalho mediático, sobretudo, definem-se, paralelamente, os modelos, os recursos e os padrões de consumo que visam "atingi-lo", orientando, numa perspetiva heteronormativa, as expectativas de afirmação e de aceitação social das consumidoras.

\section{Considerações finais}

Partir do pressuposto de que a luta feminista seja algo adquirido e já ultrapassado, tendo caído em desuso, abre precedentes para que a força e o espírito de 
contestação também caiam em desuso e, acima de tudo, para que se enfraqueça a tentativa ainda muito urgente de se repensar as definições mediáticas de feminilidade (e também de masculinidade). A análise dessas definições poderá trazer um avanço significativo para o debate em torno de políticas mais inclusivas e objetivas de igualdade de género, trazendo para o jornalismo o combate e a erradicação dos estereótipos de género a partir de uma ética de responsabilidade deontológica dessa profissão. E os desdobramentos dessa resistência na narrativa mediática quanto à luta feminista ainda dão os seus sinais hoje em dia: é patente uma real ofensiva ideológica contra os feminismos bem como, nesta senda, a existência de repressão de tentativas de estabelecimento de novos modelos de comunicação que ofereçam representações menos estereotipadas e mais integradoras e positivas das mulheres, jovens ou não, na sociedade mediatizada.

No fundo, a representação que os media fazem dos feminismos nos dias de hoje, ou dos pós-feminismos, é a que mais se aproxima do modelo "neoliberal e individualista da mulher contemporânea", como explicou Magalhães (2011), noutras palavras, a que mais defende e perpetua os valores que 0 discurso ideológico tanto aprecia. Neste processo de apropriação/adaptação dos feminismos aos moldes neoliberais de hoje, surge ainda uma outra modalidade, que, como explica Magalhães, vende a ideia de se "melhorar as vivências e as experiências", mas, na verdade, é restrito e associado a uma parcela privilegiada da população: 0 "feminismo elitista". Este feminismo é ligado à cultura popular e, portanto, conhecido como feminismo popular (pop feminism).

Se nos basearmos na análise que McRobbie faz sobre esta questão, o que se identifica nesta ofensiva ideológica do neoliberalismo é um discurso ancorado em mecanismos de repressão para neutralizar as correntes feministas e construir outros significados ao redor deste termo, mais leves, aceitáveis e "inofensivos". Tais significados devem operar em consonância com a retórica de uma imagem constantemente trabalhada pelos media: a de mulheres com liderança, fortes e determinadas, mas, acima de tudo, sensuais (e femininas). Como sublinhou a este propósito McRobbie, as diversas instâncias mediáticas hoje no mercado, em nome da pretensa "democracia" das diferenças, já aqui mencionada, optam pela abordagem de alguns temas da agenda feministas e na ordem do dia, mas não de os aprofundar, através de "more acceptable forms of feminism that entered the realms of common sense" (2011: 179).

Quando se fala da criação e da difusão de formas mais aceitáveis dos feminismos - ou como os próprios media enaltecem, um "novo feminismo", com espírito de liderança e ênfase no individualismo - expomos as fissuras de um sistema de estrutura sexista, patriarcal e heteronormativo, assente numa retórica neutralizante das políticas de igualdade de género.

0 panorama desenhado até 0 momento marca o horizonte de um processo hegemónico bem mais complexo, que assenta na ideia orientadora da hegemonia de poderes, como tentei demostrar nas páginas anteriores, ou de uma certa "governabilidade quotidiana", tomando novamente as palavras de Foucault e de McRobbie, por meio do controlo da informação e, nesta senda, da manipulação da linguagem enquanto mecanismo de controlo da opinião pública e de concessão de escolhas e de poderes. Esta constatação leva-nos a uma reflexão sobre o impacto da construção economicista dos referenciais de feminilidade apropriados tanto pelas re- 
vistas como pelo mercado publicitário, duas instâncias mediáticas que consolidam os modelos hegemónicos de feminilidade e de masculinidade, orientando, assim, a construção identitária dos sujeitos.

\section{Bibliografia}

Arús, Marta et al. (2000), El Sexo de la Noticia: Reflexiones sobre el género en la información y recomendaciones de estilo. Barcelona: Icaria.

Biroli, Flávia (2010), “Mulheres e política nas notícias. Estereótipos de género e competência política", in Rev. Crítica de Ciências Sociais. Coimbra: CES, n 90, 45-69.

Carter, Cynthia; Steiner, Linda (2003), Critical Readings: Media and Gender (Issues in Cultural and Media Studies). Michigan: Open University Press.

El Yamani, Myriame (1998), Médias et Féminismes: Minoritaires sans paroles. Paris: L'Harmattan.

Faludi, Susan (1993), Backlash: The Underclared War Against Women. New York: Three Rivers Press.

Fraser, Nancy (2009), "O Feminismo, o Capitalismo e a Astúcia da História", in Contribuições do Pensamento Feminista para as Ciências Sociais. Mediações Londrina, vol. 14, $n^{0}$ 2, 11-33 (originalmente publicado na New Left Review, 56, Março-Abril, 2009, sob o título Feminism, capitalism and the cunning of history.

Gallego, Juana (2004), "Produção informativa e transmissão de estereótipos de género", in Maria João Silveirinha (org.), As Mulheres e os Media. Lisboa: Livros Horizonte, 55-67. Macedo, Ana Gabriela; Amaral, Ana Luísa (orgs.) (2005), Dicionário da Crítica Feminista. Porto: Edições Afrontamento.

Magalhães, Sara Isabel Almeida (2011), Como ser uma Ragazza: Discursos de sexualidade numa revista para raparigas adolescentes. Tese de Doutoramento em Psicologia da Educação, Universidade do Minho/Braga.

McLuhan, Marshall (2001), Understanding the Media. London: Routledge.

McRobbie, Angela (2011), "Beyond post-feminism", in Public Policy Research. vol. 18, $n^{\circ}$ 3, 179-184.

Nogueira, Conceição; Silva, Sofia M. (2003), Um Olhar sobre os Feminismos: Pensar a Democracia no Mundo da Vida. Porto: Edições UMAR.

Silveirinha, Maria João (2001), "0 discurso feminista e os estudos dos media: em busca da ligação necessária", in Faces de Eva. Universidade Nova de Lisboa/Edições Colibri, vol. 6, 65-84.

Silveirinha, Maria João (2004), "Os media e as mulheres: horizontes de representação, de construção e de práticas significantes", in Maria João Silveirinha (org.), As mulheres e os Media. Lisboa, Livros Horizonte: 5-12.

Thornhan, Sue (2006), Women, Feminism and Media. Edinburg: Edinburg University Press. Van Zoonen, Elisabeth A (1992), "The Women's Movement and the Media: Constructing a Public Identity", in European Journal of Communication. Sage: London, vol. 7, 453-476. Van Zoonen, Elisabeth A (2000), Feminist Media Studies. London: Sage Publications. Van Zoonen, Elisabeth A (2004), “0 Movimento das Mulheres e os Media: A Construção de 
uma Identidade Pública", in Maria João Silveirinha (org.), As Mulheres e os Media. Lisboa: Livros Horizonte, 155-174.

Ventura, Isabel (2012), As Primeiras Mulheres Repórteres. Portugal nos anos 60 e 70. Lisboa: Tinta da China.

Wittig, Monique (1992), The Straight Mind and other essays: Women's studies, Gay and lesbian studies. Michigan: Editora Harvester Wheatsheaf.

Winship, Janice (1987), Inside Women's Magazine. London: Pandora Press.

Wolf, Naomi (1992), o Mito da Beleza: como as imagens de beleza são usadas contra as mulheres. Rio de Janeiro: Rocco.

Juliana Mello Sousa - É jornalista, redatora e produtora. Doutorou-se, em 2016, em "Linguagens e Heterodoxias" Universidade de Coimbra/Portugal. É membro do Centro de Estudos Sociais (CES) da Universidade de Coimbra. É ativista feminista e é membro da UBM (União Brasileira de Mulheres)

Data de recepção do artigo/ Received for publication: 20.12.2016

Data de aceitação do artigo/ Accepted in revised form: 20.02.2017 